\title{
Seeking tourism sustainability - A case study of Tioman Island, Malaysia
}

\begin{abstract}
This study evaluates Tioman Island's sustainability achievement using the Sustainable Ecotourism Indicator System (SEIS). Sustainability is achieved if each stakeholder makes a positive contribution to others in social, environmental, and economic dimensions. The overall sustainability score allows objective comparisons across destinations, which may provoke positive reactions from stakeholders to play their parts. Three questionnaire versions were designed in which each stakeholder group (39 government officers, 104 local communities, and 105 tourists) rated their perceptions of sustainable relationships with two other stakeholder groups, resulting in six sustainable relationship aspects. The results indicate that Tioman Island is classified as "potentially sustainable" (58.89\%).
\end{abstract}

Keyword: $\quad$ Island tourism; Stakeholder; Tourism indicators; Sustainable 